Psicologia Escolar

e Educacional
ARTIGO

DOI: http://dx.doi.org/10.1590/2175-35392021226634

Localizador - e226634

\title{
ESCRITA CRIATIVA E AUTORAL ENTRE UNIVERSITÁRIOS/AS: RELAÇÕES ESTÉTICAS E BIVOCALIDADE
}

\author{
Graziele Aline Zonta ${ }^{1} \mathbb{D}$; Andrea Vieira Zanella ${ }^{2} \mathbb{D}$
}

\section{RESUMO}

Este estudo analisa os processos de criação e autoria nas práticas acadêmicas de estudantes de graduação. Delineado no formato de pesquisa-intervenção, o estudo foi desenvolvido a partir de oficinas de leitura e escrita realizadas com estudantes de duas universidades federais brasileiras. As falas e textos produzidos pelos/as estudantes foram analisados discursivamente a partir de fundamentos de Bakhtin e de Vygotski e revelaram que o exercício de apropriação de novos modos de escrita é significado como um risco pelos/as discentes, que produzem seus textos responsivamente às práticas avaliativas. Indicam também que eles/as parecem desconhecer a dimensão criativa de suas produções, limitando a criação acadêmica à repetição de conceitos, restrições de formato e citações. Por outro lado, a escrita ganha traços de autoria e criação quando o conteúdo estudado é articulado às suas experiências e contextos sociais.

Palavras-chave: letramento; oficina criativa; autoria

\section{Creative and authorial writing among university students: aesthetic relations and bivocality}

\begin{abstract}
This study analyzes the creation and authorship processes in the academic practices of undergraduate students. Designed in the research-intervention format, the study was developed from reading and writing workshops held with students from two Brazilian federal universities. The speeches and texts produced by the students were analyzed discursively based on Bakhtin and Vygotski's foundations and revealed that the exercise of appropriation of new ways of writing is perceived as a risk by the students, who produce their texts responsively to evaluative practices. They also indicate that they seem to be unaware of the creative dimension of their productions, limiting academic creation to repetition of concepts, format restrictions and citations. On the other hand, writing gains authorship and creation traits when the studied content is articulated to their experiences and social contexts.
\end{abstract}

Keywords: literacy; creative workshop; authorship

\section{Escrita creativa y autoral entre universitarios/as: relaciones estéticas y bivocalidad RESUMEN}

En este estudio se analiza los procesos de creación y autoría en las prácticas académicas de estudiantes universitarios. Delineado en el formato de investigación-intervención, el estudio fue desarrollado a partir de talleres de lectura y escritura realizadas con estudiantes de universidades federales brasileñas. Las hablas y textos producidos por los estudiantes fueron analizados discursivamente a partir de fundamentos de Bakhtin y de Vygotski y revelaron que el ejercicio de apropiación de nuevos modos de escritura es significado como un riesgo por los discentes, los cuales producen sus textos responsivamente a las prácticas evaluativas. Indican también que ellos parecen desconocer la dimensión creativa de sus producciones, limitando la creación académica a la repetición de conceptos, restricciones de formato y citaciones. Por otro lado, la escritura gana trazos de autoría y creación cuando el contenido estudiado es articulado a sus experiencias y contextos sociales.

Palabras clave: instrucción académica; taller creativo; autoría

\footnotetext{
${ }^{1}$ Universidade Federal do Paraná - Curitiba - PR - Brasil; gzonta@hotmail.com

${ }^{2}$ Universidade Federal de Santa Catarina - Florianópolis - SC - Brasil; avzanella@gmail.com
} 


\section{INTRODUÇÃO}

A leitura e a escrita de artigos científicos, manuais e capítulos de livros são atividades desenvolvidas por estudantes de graduação nas diferentes áreas de formação. O presente trabalho, inserido no campo de estudos do letramento acadêmico (Henderson \& Hirst, 2007), focaliza como os usos da linguagem escrita na universidade, mais do que instrumentalizarem para a produção de atividades acadêmicas, são fundamentais para a formação de leitores-escritores criativos e autorizados.

Nessa perspectiva, entendemos que a linguagem escrita é objetivação do/a autor/a no texto produzido e, simultaneamente, é constitutiva da sua subjetividade (Munhoz, 2010; Ortiz, 2010; Zanella, 2013). Por engendrarem a criação de novos sentidos em um complexo processo que envolve consciência, intencionalidade, pensamentos e afetos, a leitura e a escrita são atividades criadoras amalgamadas ao processo psicológico da imaginação, sendo por meio das experiências do sujeito em contextos culturais específicos, que esse processo se movimenta (Vigotski, 2009).

Ademais, leitura e escrita são mediadas por um tipo particular de relação que se estabelece entre pessoas, entre pessoas e objetos, entre pessoas e o próprio mundo em que vivem: a relação estética. Para Zanella (2013), a relação estética é o que possibilita o estranhamento daquilo que é conhecido, a reinvenção do costumeiro, vislumbrando possibilidades de devir. Por meio de relações estéticas superamos o que nos é apresentado como dado e exercitamos novos modos de ver.

Podemos estabelecer relações estéticas com a linguagem escrita, tanto na condição de leitores/as, quanto de escritores/as. A condição de leitores/as exige que assumamos não uma postura passiva de compreensão dos elementos que o/a autor/a do texto lido registrou em sua obra, mas um movimento de reconstrução dos sentidos, movimento esse que Vigotsky (2001) denominou como "síntese criadora secundária" (p. 334).

$\mathrm{Na}$ condição de escritores/as, o escrever se realiza como síntese secundária possível a partir das leituras realizadas, mas não somente dessas, pois as leituras de textos e experiências outras se entretecem no processo de criação. Desse modo, ler e escrever permitem experimentar diferentes modos de uso da linguagem, problematizá-los e assim perceber como nos inserimos e circulamos pelas práticas que envolvem a linguagem escrita nos diferentes contextos dos quais participamos. Esse, defendemos, é um processo que favorece o reconhecimento da autoria do/a leitor/a-escritor/a.

Na perspectiva de Bakhtin (2003; 2012), os conceitos de autoria e criação estão articulados ao posicionamento ativo, responsável, ético-estético entre sujeitos e objetos em relação. "Compreender um objeto significa compreender meu dever em relação a ele (a orientação que preciso assumir em relação a ele), compreendê-lo em relação a mim na singularidade do existir-evento" (Bakhtin, 2012, p. 66). Como nos encontramos exotopicamente distanciados, damos aos outros, pessoas e objetos, o acabamento estético que a nós mesmos não podemos dar e, assim, do nosso lugar único e insubstituível, conhecemos, avaliamos, significamos e criamos o/no mundo. Logo, para Bakhtin (2012), não é possível a existência de uma verdade incontestável, já que sua validade é reconhecida não pelo conteúdo tomado abstratamente, mas pela sua correlação com o lugar singular daquele que o manifesta como um enunciado.

Nessa orientação, a partir do conceito de bivocalidade, Bakhtin (2013) indica que mesmo a repetição das palavras do outro se concretiza como um processo criativo, revestido de algo novo, ao mesmo tempo em que se ampara em algo já conhecido, nas palavras que o antecederam. Nesse processo, nossas vozes se imiscuem com as vozes dos outros, construindo os campos discursivos nos quais nos inserimos (Bakhtin, 2013).

Dessa maneira, a concepção de leitura como decodificação de sentidos finais impressos nos textos torna-se inviável, já que o texto não pode ser reduzido a relações concreto-semânticas. Para além das relações linguísticas, o ler-escrever se apresenta como prática mediadora das relações entre sujeitos, como diálogo entre as vozes de autores que objetivam suas ideias e valores nos textos escritos e leitores que os acessam e refratam no próprio processo de ler, construindo um processo polissêmico e polifônico (Bakhtin \& Voloshínov, 2006; Bakhtin, 2013).

No contexto acadêmico, entendemos que as atividades de escrita envolvem o/a estudante ativamente na apropriação de leituras e na produção de textos em resposta às demandas acadêmicas, pois os/as lançam na criação de contrapalavras que produzem efeitos de subjetivação. À vista disso, em nossa análise lançaremos um olhar para o modo como estudantes vivenciam e significam as práticas de leitura e escrita acadêmicas, buscando compreender o que para eles/as se interpõe como obstáculos para a criação e para o reconhecimento da autoria nessas práticas.

\section{MÉTODO}

Nosso estudo parte das informações produzidas junto a estudantes de graduação da Universidade Federal de Santa Catarina (UFSC) e da Universidade Federal do Paraná (UFPR) que participaram de oficinas de leitura e escrita oferecidas nessas instituições, no ano de 2016. Estruturadas no formato de pesquisa-intervenção (Dias, Zanella, \& Tittoni, 2017) as oficinas foram mediadas por uma psicóloga que atua em serviço de assistência estudantil em uma universidade pública. Foram organizados três grupos de estudantes (dois na UFSC e um na UFPR) com um número de encontros que variou entre seis e oito, abordando temas que entreteciam as práticas de 
produção acadêmica e as relações que se estabelecem na universidade mediadas por tais práticas. Em cada oficina eram propostas leituras e produções escritas de diferentes tipos de textos (acadêmicos, literários, redes sociais) e rodas de conversa sobre as condições de criação desses textos, buscando problematizar o diálogo entre vozes que os textos concretizam e suas inter-relações com o cotidiano acadêmico.

As falas das participantes ${ }^{1}$, as quais foram registradas em gravador e posteriormente transcritas, e os textos por elas produzidos nos encontros, serviram de base para a análise discursiva orientada pelos constructos de Vigotsky e Bakhtin, que está aqui apresentada. Por meio desse método, buscamos analisar os sentidos produzidos pelas participantes, seu posicionamento axiológico (Bakhtin, 2003; 2013) sobre as práticas de leitura e escrita acadêmicas, de modo a engendrar uma discussão sobre as possibilidades de criação e autoria nessas práticas.

\section{Criar(se) é arriscar(se)}

Durante das oficinas, as propostas de atividades escritas a serem realizadas pelas participantes abordavam os temas trabalhados em cada encontro. Não havia avaliação dos textos, ou qualquer tipo de punição ou recompensa pelos resultados. Nosso foco estava em conversarmos sobre como cada participante se relacionava com os textos, quais as dificuldades e facilidades que emergiam do processo de ler-escrever. Também não havia a obrigação de ler para as colegas os textos produzidos, se assim não o desejassem. Com essas estratégias, tentamos criar um ambiente livre do crivo avaliativo comum ao contexto da sala de aula e proporcionar um espaço onde as escritoras pudessem ousar produzir diferentes textos, significá-los, reconhecendo-se como autoras.

No entanto, ainda que todas essas possibilidades fossem apresentadas e discutidas, uma inquietação se manifestava sempre que chegava o momento de passarmos da roda de conversa para a escrita. Ao convite da mediadora - "Vamos escrever?" - as participantes respondiam suspirando, se endireitando na cadeira, ajeitando seus materiais e perguntando em tom ansioso, às vezes todas ao mesmo tempo:

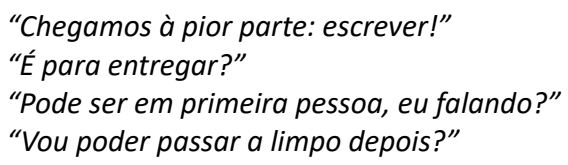

$\mathrm{O}$ que esses enunciados/sentidos nos falam sobre o escrever para as participantes? Estudos que versam

\footnotetext{
${ }^{1}$ Optamos por nos referir às participantes no gênero feminino, pois eram na sua maioria mulheres. Foi a elas oferecida a possibilidade de serem referenciadas pelos seus próprios nomes, pelas iniciais dos nomes ou por pseudônimos por elas criados, sendo que a opção de cada uma foi respeitada no presente artigo.
}

sobre as práticas de letramento nos contextos de escolarização formal nos mostram que o desconcerto gerado pelo momento de escrever não é exclusivo do ensino superior. Ao contrário, acompanha o movimento dos níveis básicos de educação que, desde cedo, associam a hora da escrita a situações de tensão:

Via de regra, o lugar mais frequente para as práticas escriptológicas dos alunos na escola é a prova, o exame ou o trabalho valendo nota. Momento em geral ansiogênico para sujeitos de qualquer idade, pois implica avaliação, isto é, o julgamento, por parte de alguém que detém as insígnias socialmente legitimadas para emitir um conceito. (Machado, 2007, p.183).

inda que a escola não seja a única responsável pela formação da autoria, já que não é só nela que o sujeito produz(se) pela linguagem escrita, é essa a instituição privilegiada para a sua promoção ou restrição. Dessa forma, "mesmo fora da escola, os sujeitos-leitores terminam por internalizar os rituais coercitivos da leitura e da escrita nela vivenciado, vincados que são pelas experiências construídas nas suas andanças discursivas pelos caminhos da escola" (Silva, 2008, p. 363). Sobre esse ponto, Olave-Arias, Rojas-García e Cisneros-Estupiñan (2013) afirmam que a avaliação a partir de textos escritos constitui uma redução perniciosa do ler e escrever na universidade, pois a função de medir o aprendizado acaba por orientar suas práticas a agradar a um professor de modo a obter a qualificação que será traduzida em um número e que, por sua vez, poderá contribuir para a sua (des)aprovação.

Podemos assumir que as práticas avaliativas que envolvem a linguagem escrita na educação formal, desde as séries iniciais até o ensino superior, se entretecem e se realizam nas respostas ansiosas das participantes quando são convidadas a escrever livremente, como ocorreu nas oficinas. Ester, estudante do curso de Terapia Ocupacional na UFPR, após ouvir a proposta de atividade escrita em um encontro das oficinas, a qual convidava a escrever sobre um tema trabalhado no seu curso de graduação, porém fazendo uso de qualquer gênero textual não acadêmico, nos fala sobre como vivencia esse processo:

Eu acho que é difícil, acho que justamente por a gente ficar se criticando demais. Eu já pensei: "ah, eu não vou conseguir, vai ficar tudo errado. Meu Deus do céu!" Eu acho que a gente é muito pressionado na faculdade a fazer tudo de um jeito, de UM jeito, que você não pode opinar, você tem que escrever daquele jeitinho. Você nem consegue pensar, ser livre para escrever. (Ester, UFPR).

A passagem pelo ensino superior se apresenta, no contexto educacional brasileiro, como o momento em 
que o letramento acadêmico ocorre, pois é nesse nível de ensino que os/as estudantes aprendem os modos de comunicação que constroem o campo específico de discursos das ciências, bem como os conhecimentos pertinentes às faculdades cursadas. Nesse sentido, as práticas de letramento acadêmico precisam envolver o ensinar-aprender da linguagem própria desse contexto, dos seus valores e modos de dizer, incluindo aqui a escrita, tanto quanto o ensino de conteúdos e cumprimento da ementa das disciplinas (Boughey, 2000). Tal apropriação precisa ser elaborada ao longo da trajetória acadêmica criando condições para a construção de uma escrita autoral e responsiva ao campo científico.

No entanto, o que Ester parece ilustrar em sua fala é a significação de que sua escrita deve responder a restrições de forma e conteúdo que são postas para a sua produção. É preciso "escrever daquele jeitinho", nos formatos pré-definidos para os trabalhos, sem liberdade na condução da sua escrita.

Quando apresentamos a atividade supracitada que buscava romper com essa lógica ao demandar uma escrita mais livre, oferecendo a possibilidade de tensionamento das noções de conteúdos certos ou errados e a orientação por formatos pré-definidos de texto, a estudante manifesta intensos sentidos de desamparo. A escrita criativa cede lugar à preocupação com a manutenção de um formato pré-definido e ao medo de fazer "tudo errado". A imposição de uma determinada forma e de um modo específico de apresentar um conteúdo, para ela, restringe a própria possibilidade de escrever.

Um relato sobre os impasses postos à escrita criativa foi também oferecido por Vick Block, estudante que na ocasião estava concluindo uma faculdade particular de Administração e iniciando o curso de Psicologia na UFSC. Para ele, as dificuldades para romper com os formatos pré-definidos ao longo da sua trajetória educacional parecem partir da apropriação de uma escrita guiada por processos de avaliação que poderiam determinar o seu (in)sucesso acadêmico:

Minha vida inteira era dissertação no vestibular. Então para mim, fazer qualquer outra coisa, é como se eu estivesse me arriscando a fracassar no vestibular. (...) A gente fica assim tão... A gente não se permite. (Vick Block, UFSC).

Ouvimos ressoar na fala de Vick Block sentidos construídos nos anos anteriores de educação formal e que são agora reinventados no ensino superior. Sua escrita escolar foi construída tendo por base os textos dissertativos e argumentativos que lhe dariam acesso à universidade, situação comum a estudantes do ensino fundamental e médio que se formam como proficientes autores/as-escritores/as do gênero redação de vestibular.

A resistência de Vick Block à criação em outros gê- neros é compreensível. Evidentemente, não esperamos que os/as estudantes aproveitem a prova de vestibular para se lançarem em produções para as quais estejam despreparados/as. Por outro lado, podemos aproveitar suas falas para questionar a orientação da escrita de nossos/as estudantes: Quais as possibilidades de uma escrita criativa orientada pelo medo de não passar no vestibular?

Quando fala sobre o Ensino Superior, Vick Block expressa vontade de apropriar-se de outras possibilidades de escrita, porém como continua submetido à avaliação dos professores, às notas das provas, à banca que avaliará o trabalho de conclusão de curso, sua produção segue conduzida pelo binário sucesso-fracasso:

Eu gostaria de poder fazer isso, eu acho que até posso, né? Mas é aquela coisa assim, você precisa entregar para uma banca. Você não quer correro risco de alguém te dar uma nota baixa. Você não quer correr vários riscos. Eu te digo mesmo, eu já vou me formar, eu já estou há um ano e meio a mais na minha graduação. É um risco que eu não quero correr. Eu próprio digo: "não, eu não faria isso nesse momento da minha vida", porque eu quero terminar o meu curso de qualquer jeito. Então fazer isso é me arriscar. (Vick Block, UFSC).

Para o estudante que domina a escrita acadêmica, como é o caso de Vick Block, ainda que sinta vontade de exercitar outros modos de escrita na academia, fazer isso seria se arriscar demais "nesse momento da sua vida". O risco, palavra tantas vezes repetida nas falas do estudante, não é concebido como projeto. Arriscar-se não assume o sentido de lançar-se ao novo, de aventurar-se em uma relação estética com o mundo, deixando-se afetar "pela simples possibilidade do encontro e do que esse, de modo imprevisível, pode possibilitar" (Zanella, 2013, p. 44).

O risco é uma ameaça ao bom desempenho, às boas notas, à aprovação no curso. Na incerteza do sucesso, é mais seguro continuar com o que já se conhece. Mas questionamos: É possível ser e sentir-se criativo/a e autor/a nas próprias práticas acadêmicas que já se conhece? É possível que as instituições educacionais, principais formadoras dos/as escritores/as, ofereçam possibilidades de reconhecimento da autoria e da criação nas atividades de leitura-escrita? Se esse processo não acontecer durante a passagem pela universidade, quando esse "momento da vida" chegará?

Aqui, assumimos que a concepção do ler e do escrever enquanto práticas sociais que inter-relacionam sujeitos e sentidos é um caminho para o reconhecimento da autoria nessas atividades. Contudo, conforme apontam Munhoz e Zanella (2008), a ênfase dada à dimensão técnica nos processos de apropriação da linguagem escrita tende a desconsiderar as possibilidades de produção 
de sentidos que essas atividades engendram. Por outro lado, práticas de apropriação da escrita que orientam para a construção de relações estéticas dos sujeitos com seus processos de produção, poderiam oferecer condições para que pudessem enxergar o texto para além das sentenças que o compõem, concebendo-o como ?uma produção inserida num determinado contexto histórico-cultural, que mobiliza lembranças, produz sensações, afetos que lhe permitem um contato diferenciado com o texto" (p. 293). Ademais, por carregarem essas escritas as marcas dessas relações estéticas de seus/suas autores/as, podem vir a provocar também esse tipo de relação em possíveis leitores/as.

Nesse sentido, é a identificação do ler-escrever enquanto apropriação e (re)criação de sentidos que possibilita o reconhecimento do/a leitor-escritor/a como produto e produtor/a, autor/a e obra da sua cultura, como expressão e fundamento do contexto social e histórico do qual participa. É o que o move a criar e recriar com a escrita.

\section{"Repetir é um dom do estilo"}

Pensamento e imaginação são processos psicológicos que catalisam, amalgamados aos afetos, a produção de sentidos, a criação (Vigotski, 2009). No entanto, como esses processos podem se realizar no texto acadêmico, responsivo às demandas dos saberes-fazeres das ciências? Partiremos para essa discussão dialogando com os sentidos que as participantes constroem sobre suas possibilidades de pensar, imaginar e criar no contexto universitário.

Alba, estudante do segundo ano de Direito na UFPR, compara sua criatividade na infância e na universidade. Aqui, observamos que as características dos contextos dos quais a estudante participou e participa são constituintes dos sentidos que produz acerca das suas práticas e de si mesma:

$$
\begin{aligned}
& \text { Eu sempre fui uma criança muito fantasiosa, } \\
& \text { minha imaginação é bem fértil. Vem do lugar } \\
& \text { que eu morei, que a gente tinha muita liberdade. } \\
& \text { A gente não tinha bonecas, eu criava as minhas } \\
& \text { bonecas com canudo de mamão, colocava o } \\
& \text { cabelinho lá... E sempre foi assim. Isso exercitou } \\
& \text { muito a minha criatividade. Agora na faculdade, } \\
& \text { eu vejo que ela está mais limitada. Porque o } \\
& \text { conteúdo é aquele conteúdo engessado que eu } \\
& \text { tenho que aprender. Eu não posso, eu não exercito } \\
& \text { muito a minha imaginação ou a criatividade } \\
& \text { porque tem que aprender a técnica, a correta } \\
& \text { maneira de falar, os termos, os conceitos. No meu } \\
& \text { curso não tem muita margem para criação. E essa } \\
& \text { coisa de entregar trabalho, provas, vocêa acaba não } \\
& \text { tendo tempo para isso. (Alba, UFPR). }
\end{aligned}
$$

Reiteramos que a dimensão criadora não é uma via de mão única, que vai somente da subjetividade do/a criador/a para a objetivação na obra criada. A criação se faz também, e mutuamente, em sentido inverso: a criação (re)cria, (trans)forma o criador (Prestes, Tunes, Pederiva, \& Terci 2018; Wedekin \& Zanella, 2018). Em sua fala, Alba não parece reconhecer onde a criatividade se insere nas práticas do seu curso, limitando-se a apropriar-se das "técnicas, da correta maneira de falar, dos termos, dos conceitos". Ela compreende que provas e trabalhos são necessários para que aprenda a concretizar produções na forma-conteúdo responsiva ao campo discursivo do seu curso, ou às demandas das disciplinas cursadas. Entretanto, não compreende que tais práticas estão, ao mesmo tempo, produzindo-a subjetivamente, mobilizando seus pensamentos e afetos, e esse é o processo fundamental para a (des) construção dos conteúdos-sentidos ensinados no curso, para um posicionamento ativo, responsivo, com relação ao processo de aprendizagem. A escrita acadêmica parece, então, descolada do mundo da vida, engessada por conteúdos-sentidos supostamente imutáveis, destituídos de historicidade e das condições de autoria.

Quando não atentamos para a dimensão criadora das práticas acadêmicas, desconsideramos a condição de que todo o conhecimento é transformado nas complexas relações afetivo-cognitivas dos sujeitos que com ele dialogam, os lugares sociais e as condições de saber/poder que balizam essas relações. Incumbimos ao conhecimento o valor de commodities, como nomeia Boughey (2000), a serem adquiridos e reproduzidos, ou como "depósitos" a serem feitos pelos/as professores/as aos/às estudantes, conforme a crítica de Paulo Freire (1987) ao modelo de educação bancária. Aqui, podemos ilustrar os efeitos de sentido desse processo com as curtas, mas incisivas falas de Dhara, estudante do primeiro ano de Pedagogia, e Júlia, estudante do quarto ano de Enfermagem, ambas da UFSC, quando citam comentários que ouviram de seus professores durante a graduação:

Você é de primeira fase, não tem que falar. Então, senta e escuta. (Dhara, UFSC).

A gente não pensa na graduação. É o que falam para a gente. Vocênão tem pensamento próprio na graduação. Você tem que sempre citar alguém. (Júlia, UFSC).

As falas de Dhara e Júlia ressonam sentidos que indicam que "citar alguém", nesse caso os/as autores/as dos textos acadêmicos, significa não ter "pensamento próprio", o que seria, segundo suas falas, compreendido pelos/as professores/as como uma condição de todo/a o/a estudante de graduação, principalmente do/a ingressante que, aparentemente desprovido/a de qualquer conhecimento, não está autorizado/a a se posicionar, devendo sentar e escutar a autoridade de saber. A prática da citação de obras, que efetiva o diálogo 
entre vozes, e que por sua vez constrói os argumentos na produção de conhecimentos, é significada pelas estudantes como reprodução, destituída de criação. Sendo assim, seriam conhecimentos afirmados por outros que pensam por elas. Aos/às estudantes de graduação, segundo as participantes da pesquisa, a condição de sujeito pensante parece ter sido renegada.

Há nesse debate questões a serem consideradas: por um lado, as estudantes exprimem por meio de suas falas o que percebem como processo de desqualificação de suas experiências, um modo de atuação docente que se assenta na hierarquização de saberes e subjugação de quem ainda não domina determinada linguagem e seus códigos. Por outro lado, compreendem que o fato de terem que escrever referindo-se a conceitos e, por conseguinte, a autores/as que os cunharam e desenvolveram, é compreendido por elas como restrição à escrita criativa. Dessa forma, é possível compreender que a noção de responsividade, enquanto posicionamento ativo frente aos conteúdos, saberes e experiências que participam da criação escrita, e que envolve as relações que medeiam as práticas de letramento acadêmico, permanece obscuro às estudantes-escritoras.

Para Alba, Dhara e Júlia, não está claro que a posição autoral e criadora é inerente aos fazeres acadêmicos. Sua escrita não parece ser compreendida como o resultado de processos criativos, como diálogo entre conceitos, como (re)criação dos sentidos objetivados nos textos, o que possibilitaria reinventá-los, transformá-los em novos (con)textos, como sínteses criadoras secundárias (Vigotsky, 2001).

Relembremos que nossos enunciados, mesmo quando parecem somente repetir as palavras do outro, revestem-se da nossa avaliação do mundo, tornando-se bivocais. Vozes outras dialogam com as nossas e podemos até nos confundir com algumas delas, mas sempre o faremos do nosso lugar singular no mundo (Bakhtin, 2013). Desse modo, indagamos se seria possível calar as contrapalavras inerentes aos enunciados das estudantes-leitoras-escritoras, ainda que estejam nos momentos iniciais do curso. Seria possível destituí-las do seu posicionamento ético-estético, único e insubstituível?

As produções das participantes da pesquisa permitem afirmar que não, ainda que os discursos/práticas contrários a essa afirmação imperem no contexto universitário. Embora a escrita dessas estudantes seja orientada a leitores/as-professores/as pré-definidos/as, buscando fixar os sentidos que imaginam responder às suas expectativas e necessários para alcançar uma boa nota, sentidos outros atravessam a produção escrita e deixam seus vestígios. Nesse processo, a (re)criação é inevitável, transcende os aspectos linguístico-estruturais dos textos e atingem as condições discursivas que compõem o "querer dizer" do seu autor (Geraldi, 2010).

Compreender que a criação está presente em tudo que nos cerca, inclusive no que aparenta ser mera imitação, é um aprendizado importante. Vigotski (1984) esclarece a importância do processo de imitação na brincadeira para o desenvolvimento infantil, pois ao imitar um adulto, a criança busca compreender essas ações e o modo como se insere no contexto social em que vive. Podemos estender essa discussão para o âmbito acadêmico para defender que a imitação de um estilo de escrita, por exemplo, é parte de um processo de constituição da própria possibilidade de autoria.

Não há aqui, importante esclarecer, equivalência entre imitação e plágio. $O$ plágio acadêmico, entendido como "apropriação indevida de um texto ou parte dele, sem referência ao autor, portanto apresentado como sendo de autoria da pessoa que dele se apodera" (Silva, 2008 , p. 360), é prática passível de punição, há legislação específica sobre o assunto. A imitação a que nos referimos, relacionada à escrita acadêmica, diz respeito ao próprio processo de constituição do/a autor/a, que se faz através de leituras, escritas, reescritas, mais leituras, escritas outras, em um processo complexo, incessante. Para que esse processo venha a acontecer na universidade,

\section{(...) é urgente criar um espaço nos entre-lugares da academia - onde geralmente se dão os embates e as ambivalências - que engendre a constituição da autoria, pois aí está o tripé que sustentará a escrita no espaço acadêmico, no qual poderão e deverão se estabelecer as relações necessárias à construção de textos pelo aprendente, este como sujeito do desejo que, ao enxergar-se como autor, institui, no mesmo ato, o leitor (Silva, 2008, p. 364).}

Entendemos que auxiliar os/as estudantes na compreensão dos processos de criação do conhecimento é também dever da universidade em suas práticas acadêmicas. Quando essa questão é negligenciada, os/ as estudantes seguem reforçando a lógica de decorar e copiar os textos, sem compreender como a criação entra nesse processo.

"Repetir repetir - até ficar diferente. Repetir é um dom do estilo". Essa é a provocação poética que Manoel de Barros (2016, p. 16) nos apresenta no livro que ganhou o expressivo título de $O$ livro das ignorãças. Lancemo-nos no desafio de transcender o campo da poesia ampliando seus sentidos para o campo das ciências, discutindo os movimentos em direção a uma escrita autoral.

O estilo é pelo menos duas pessoas ou, mais precisamente, uma pessoa mais seu grupo social na forma do seu representante autorizado, o ouvinte - o participante constante na fala interior e exterior de uma pessoa (Bakhtin \& Voloshinov, 1976, p. 15). 
Sem nos atermos a uma discussão acerca de teorias que versam sobre o estilo, estudo que fugiria ao escopo da nossa análise, vamos partir do enunciado de Bakhtin e Voloshinov para abordar a escrita como a transformação da fala interna de um/a autor/a que, localizado/a em determinado contexto social, dialoga sobre um tema com os/as demais participantes desse contexto, sejam eles/as participantes reais no mundo da vida, ou imaginados, apropriados desse mundo pelo/a autor/a.

Para nos ajudar nesse ponto, contaremos com o depoimento de Larisse, estudante do segundo ano de Turismo na UFPR. Em uma roda de conversa, a estudante relatou um momento em que se sentiu autorizada em sua escrita acadêmica:

Essa semana uma menina da PUC, de Jornalismo, me chamou para ajudar a fazer um trabalho em que ela precisava de mulheres negras e feministas. Aí eu escolhi falar sobre colorismo ${ }^{2}$. Ela me passou quatro perguntas e eu escrevi umas dez páginas de resposta e aquilo para mim foi muito bom... Eu até tenho certo conhecimento sobre o colorismo, mas eu achei que eu ia precisar de mais embasamento, então eu ia começar a ler outros textos para ver se ia estar certo o que eu estava escrevendo. Aí eu comecei a escrever e falei: "meu, eu não vou me basear em ninguém". Eu nunca tinha feito, eu tinha vontade de escrever o que eu sei (...) E esse exercício de você escrever uma coisa que você sabe e organizar os seus pensamentos na escrita é muito bom porque eu vi que eu tenho domínio, eu sei de muitas coisas que nem eu não sabia que eu tinha, que eu sabia. E eu achei que eu ia precisar da ajuda de alguém e eu não precisava daquilo porque eu já sei. Só que como às vezes a gente não fala tanto sobre aquilo, fica só lendo, lendo, absorvendo, você não expõe... E quando você escreve você tem aquilo mais concreto. (...) Foi uma coisa que eu gostei bastante, me surpreendi. (Larisse, UFPR).

O motor que coloca em movimento a ação de escrever dez páginas sem saber que teria tanto a dizer, reconhecemos como a base afetivo-volitiva (Vigotski, 2009) que impulsionou Larisse a uma escrita autoral. Os passos para essa realização compõem um processo, a nosso ver, complexo e com origens sociais.

Afirmam Bakhtin e Voloshinov (1976): "qualquer locução realmente dita em voz alta ou escrita para uma comunicação inteligível [...] é a expressão e o produto da interação social de três participantes: o falante (autor), o

\footnotetext{
${ }^{2}$ De acordo com Nascimento (2015), o colorismo é um "sistema de segregação intrarracial baseado na tonalidade da pele" processo que estabelece a "pigmentocracia", ou seja, "o privilégio da pele clara (light skin) em relação à escura (dark skin) no tocante às oportunidades de mobilidade social" ( $p$. 155).
}

interlocutor (leitor) e o tópico (o que ou o quem) da fala (o herói)" (pp. 8-9, grifos do autor). É nessa relação que se encontra o solo no qual o querer dizer de Larisse se realiza como raízes-palavras de uma escrita autorizada.

"Eu não vou me embasar em ninguém", disse Larisse. No entanto, para nós, fica claro que o embasamento está aí presumido quando ela percebe que já "tinha domínio" de "muitas coisas que nem sabia". O conteúdo formal para subsidiar a sua escrita já havia sido apropriado, mas é ao começar a escrever que Larisse descobre que já conhece bem o herói do seu texto: o colorismo, um tema que Ihe afeta, que a mobiliza porque fala da sua existência social ${ }^{3}$. Assim, ela encontra na escritura do texto a possibilidade de se posicionar ativamente com relação a esse conteúdo apropriado e de direcionar seus pensamentos-afetos sobre o tema para um público que será ouvinte - aliado, testemunha, adversário - do seu posicionamento.

No exercício de ficar "só lendo, lendo, absorvendo", ou repetindo, repetindo, tal como propõe o poema de Manoel de Barros, Larisse tornou suas as vozes dos/as autores/as que versam sobre o colorismo e produziu um texto próprio, diferente. Ao ser convidada a escrever sobre o tema, liberta-se para falar "sem precisar de alguém", porque esse "alguém" não é mais necessário na relação concreta e imediata para auxiliá-la. Os outros que anteriormente ampararam sua escrita tornaram-se, agora, parceiros de diálogo e ganharam lugar nas vozes objetivadas no texto que ela criou sobre o colorismo. Nesse processo, ela se surpreende com sua capacidade para dar forma ao herói-conteúdo no texto, lançando sobre ele um novo olhar, que não é mais de simples repetição, mas um olhar estético que possibilitou amalgamar os seus sentidos singulares aos conteúdos estudados, envolvendo-se em uma escrita que ganhou traços de uma produção criativa, autoral.

Ainda sobre esse processo, podemos avaliar que Larisse percebeu que quando direciona sua leitura-escritura para assuntos que lhe mobilizam afetivamente, apropria-se do conhecimento dos textos com interesse e posiciona-se com relação aos conteúdos-sentidos com mais facilidade. Sobre temas que Ihe afetam, há um querer dizer.

A experiência relatada por Larisse indica-nos que a autoria foi reconhecida quando o conteúdo estudado foi entretecido às condições de existência e suas experiências sociais, encontrando condições para ser apropriado como parte de si e objetivado na produção escrita.

\section{CONSIDERAÇÕES FINAIS}

A questão da escrita autoral e criativa posta na arena dos debates da produção acadêmica exige reconhecer criação e autoria como lugares de difícil acesso e para

\footnotetext{
${ }^{3}$ Ao longo das oficinas, Larisse se posicionou ativamente como mulher negra, apontando as barreiras que a instituição universitária impõe à sua formação.
} 
os quais não há caminhos precisos a trilhar.

No movimento de produção de sentidos sobre o ler-escrever, o desconhecimento da autoria dos/as estudantes sobre as próprias produções apresenta-se articulado aos modos de fazer e dizer a eles/as postos nas práticas de letramento acadêmico e às condições de sucesso e fracasso a elas associadas. Esse processo culmina na desautorização de suas vozes nos textos e no medo de se arriscarem em outras possibilidades de escrita.

Para auxiliar os/as discentes nos seus processos de constituição como autores/as-escritores/as-criadores/ as, parece-nos fundamental o investimento em práticas que favoreçam a reflexão sobre diferentes usos da linguagem escrita e o reconhecimento dos conteúdos que lhes são familiares, ou estranhos, dialogando-os de modo a tornar próprias as vozes que compõem os textos estudados. É imprescindível considerarmos que nessa complexa relação, afetos, pensamentos e sentidos são tensionados, anunciados e replicados em um processo que necessariamente envolve a participação ativa e criativa de docentes e discentes.

\section{REFERÊNCIAS}

Bakhtin, M. (2003). Estética da criação verbal (4ª ed., P. Bezerra, Trad.). São Paulo: Martins Fontes. Trabalho original publicado em 1979.

Bakhtin, M. M. (2012). Para uma filosofia do ato responsável ( $2^{\text {a }}$ ed., V. Miotello, Trad.). São Carlos: Pedro \& João Editores. Trabalho original publicado em 1920.

Bakhtin, M. M. (2013). Problemas da poética de Dostoiévski (5a ed., P. Bezerra, Trad.). Rio de Janeiro: Forense Universitária. Trabalho original: Problémi poétiki Dostoiévskovo.

Barros, M. de. (2016). O livro das ignorãças. Rio de Janeiro: Alfaguara.

Boughey, C. (2000). Multiple metaphors in an understanding of academic literacy. Teachers and Teaching, 6(3). DOI:10.1080/713698740

Dias, L. R. R.; Zanella, A. V.; Tittoni, J. (2017). Oficinas de fotografia na pesquisa-intervenção: construção de coletivos de trabalho. Revista Nupem, 9(16), 158-174.

Freire, P. (1987). A importância do ato de ler: em três artigos que se completam. São Paulo: Cortez.

Geraldi, J. W. (2010). A aula como acontecimento. São Carlos: Pedro \& João Editores.

Henderson, R.; Hirst, E. (2007). Reframing academic literacy: re-examining a short-course for "disadvantaged" tertiary students. English Teaching: Practice and Critique, 6(2), 25-38.

Machado, A. M. N. (2007). Do modelo ao estilo: possibilidades de autoria em contextos acadêmico-científicos. In: E. Calil
(Ed.), Trilhas da escrita: Autoria, leitura e ensino (pp. 171206). São Paulo: Cortez.

Munhoz, S. C. D. (2010). Ler e escrever: palavras que se enredam na técnica e na imaginação. In: A. V. Zanella; K. Maheirie (Eds.), Diálogos em psicologia social e arte (pp. 275-287). Curitiba: Editora CRV.

Munhoz, C. D. M.; Zanella, A. V. (2008). Linguagem escrita e relações estéticas: algumas considerações. Psicologia em Estudo, 13(2). 287-295.

Nascimento, G. X. da C. (2015). Os perigos dos negros brancos: cultura mulata, classe e beleza eugênica no pós-emancipação (EUA, 1900-1920). Revista Brasileira de História, 35(69), 155-176. https://doi.org/10.1590/1806$93472015 v 35 n 69008$

Olave-Arias, G.; Rojas-García, I.; Cisneros-Estupiñán, M. (2013). Deserción universitaria y alfabetización académica. Educación y Educadores, 16(3), 455-471.

Ortiz, I. M. (2010). A leitura literária e jornalística no processo de constituição do leitor. In: A.V. Zanella; K. Maheirie (Eds.), Diálogos em psicologia social e arte (pp. 143-155). Curitiba: Editora CRV.

Prestes, Z. R.; Tunes, E.; Pederiva, P. L. M.; Terci, C. (2018). A emergência da reação estética da criança na atividade musical. Fractal: Revista de Psicologia, 30(1), 46-57. https:// doi.org/10.22409/1984-0292/v30i1/1496

Silva, O. S. F. (2008). Entre o plágio e a autoria: qual o papel da universidade?. Revista Brasileira de Educação, 13(38), p.357 - 414.

Vigotsky, L. S. (1984). O papel do brinquedo no desenvolvimento. In: A formação social da mente (pp. 121-137.) (J. C. Pipolla Neto; L. S. M. Barreto; S. C. Afeche, Trad.). São Paulo: Martins Fontes. Trabalho original publicado em 1984.

Vigotsky, L. S. (2001). Psicologia pedagógica (P. Bezerra, Trad.). São Paulo: Martins Fontes. Trabalho original: Pedagoguitcheskaia psirrologuia.

Vigotski, L. S. (2009). Imaginação e criação na infância: ensaio psicológico: livro para professores. (Z. Prestes, Trad.). São Paulo: Ática. Trabalho original publicado em 1930.

Voloshinov, V. N.; Bakhtin, M. M. (s.d.). Discurso na vida e na arte: sobre a poética sociológica. Tradução para uso didático. (C. A. Faraco; C. Tezza, Trad.). Trabalho original: Discourse in life and Discourse in art - concerning sociological poetics.

Wedekin, L. M.; Zanella, A. V. (2018). Problematizando o ensino de artes na educação regular: contribuições de Lev Vigotski. In: P. L. M. Pederiva; D. Barros; S. Pequeno (Eds.), Educar na perspectiva histórico-cultural: diálogos vigotskianos (pp.79-102). Campinas: Mercado de Letras.

Zanella, A. V. (2013). Perguntar, registrar, escrever: inquietações metodológicas. Porto Alegre: Sulina. Editora da UFRGS. 